\title{
Changes in Earth's Gravity Reveal Changes in Groundwater Storage
}

\author{
Changes in the amount of water stored in underground aquifers cause small changes in Earth's gravitational field. \\ The U.S. Geological Survey's Southwest Gravity Program has developed methods for measuring terrestrial gravity \\ changes with part-per-billion precision. The measurements allow scientists to map changes in groundwater storage and \\ to improve models that simulate groundwater flow.
}

\section{Introduction}

Newton's Law of Universal Gravitation says that the acceleration due to gravity at any point depends on the surrounding mass. When the mass of an aquifer changes, either by recharge or by discharge to surface water or wells, the gravitational acceleration at the land surface also changes. Although this change is small, it is detectable with highly precise instruments. In addition to groundwater, gravity measurements are sensitive to Earth tides, barometric pressure changes, mass changes from volcanism, and other effects. Most of these can be accounted for, or are negligible, in groundwater studies. [Continued on page 3]

\section{Gravity meter}

As generalized in this image, a gravity measurement is sensitive to a cone-shaped region of the subsurface — as depth increases, the sensitivity to individual water molecules decreases, but the region of sensitivity expands. The result is that for a given height of water-storage change, the corresponding gravity change is the same $\left(1\right.$ meter of water $=42 \times 10^{-8}$ meters per second squared), regardless of whether the water is stored near the land surface or at depth. The amount of gravity change is also independent of the porosity of the aquifer or soil.

\section{How is Gravity Measured?}

The USGS Southwest Gravity Program uses three types of gravity meters to measure gravity change at the Earth's surface —relative, absolute, and superconducting gravity meters. In addition to land-based measurements, gravity changes can also be measured by satellite. These sources provide similar data, but land-based measurements provide finer spatial resolution with lower accuracy than satellite measurements, which are highly accurate but provide only a single, average value of water-storage changes over several thousand square kilometers. (USGS photographs by Michael Landrum and Jeffrey Kennedy.)

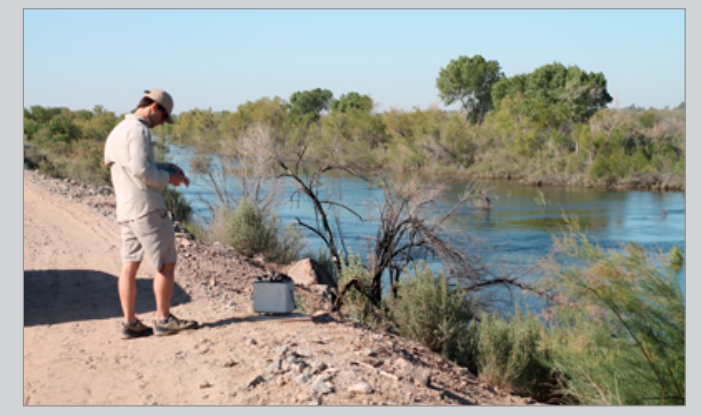

Relative-gravity meters measure differences in the force exerted on a mechanical spring as the meter is moved from place to place. These meters are highly portable but require extreme care during field surveys to minimize random drift and offsets in readings.

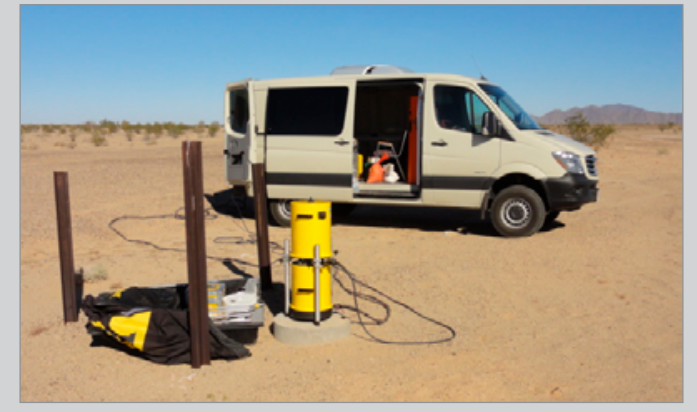

Absolute-gravity meters measure the acceleration of a mass falling in a vacuum, using a laser interferometer to measure distance and an atomic oscillator to measure time. They provide a direct measurement of the absolute force of gravity (about 9.8 meters per second squared).

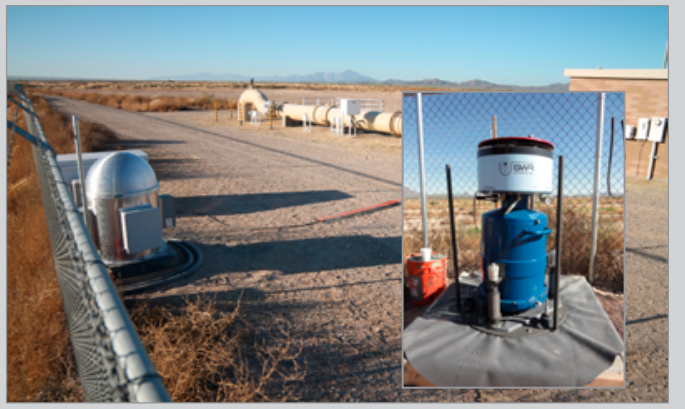

Superconducting gravity meters measure changes in the force required to levitate a sphere within a magnetic field. Because of the superconducting characteristic of the meters, the magnetic field is highly stable, and part-per-billion accuracy can be maintained over many years. (Inset shows detailed view.) 


\section{Gravity Changes Immediately in Response to Infiltration}
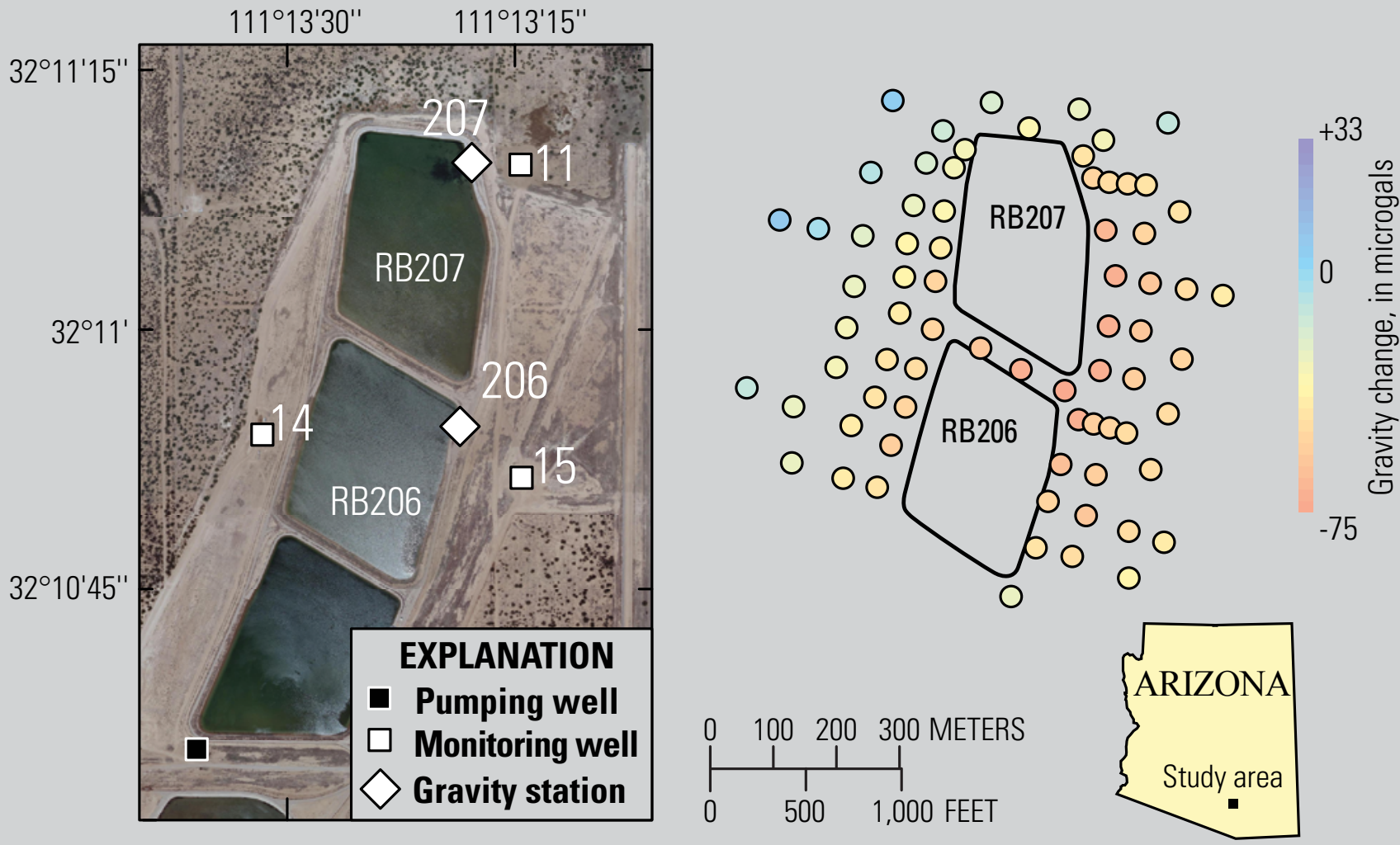

Gravity measurements reveal storage changes in the aquifer underlying groundwater recharge basins of the Southern Avra Valley Storage and Recovery Project of the City of Tucson, Arizona. The map above shows an aerial view of three of the recharge basins $(\mathrm{RB})$ and gravity change between recharge periods during a March to April 2013 drying cycle. The graphs below compare infiltration from the basins, gravity change, and groundwater-elevation change from spring 2012 to spring 2013. Gravity changes were immediate in response to infiltration in the basin adjacent to each gravity meter, whereas groundwater levels changed gradually in response to infiltration in all nine basins at the facility, as well as to other hydrologic processes in the region. The lack of accumulated gravity change after 13 months of recharge shows that the facility is transmitting water efficiently through the unsaturated zone above the water table. (Modified from Kennedy and others, 2016a.)

\section{Infiltration from filled basins}
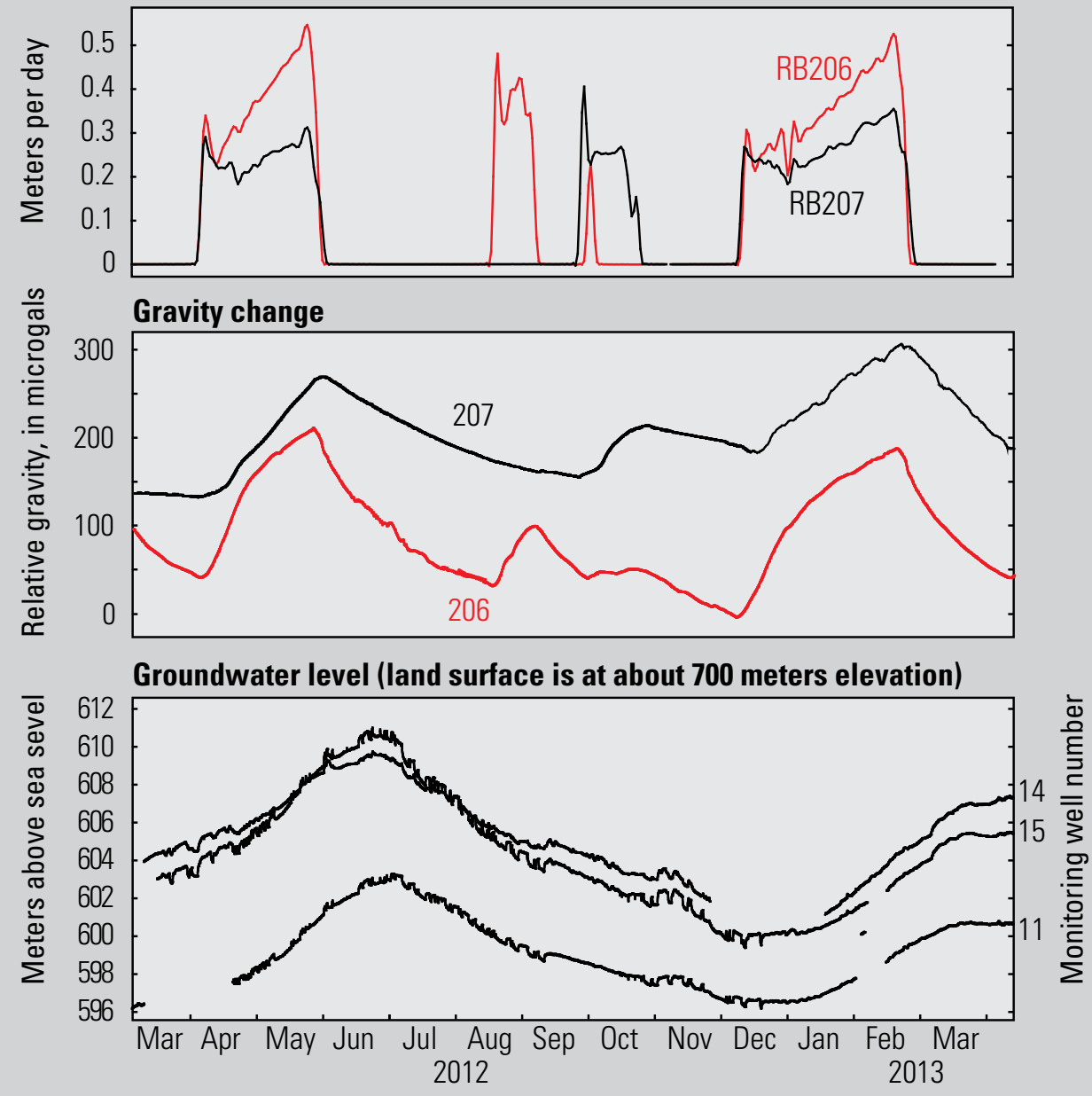
Since the 1980s, the U.S. Geological Survey (USGS) has developed field methods, software, and analytical procedures for using gravity data to aid in hydrologic investigations. Scientists with the USGS Southwest Gravity Program can measure terrestrial gravity changes with part-per-billion precision to map changes in groundwater storage and to improve models that simulate groundwater flow.

\section{Depth to Groundwater Versus Gravity Change}

Changes in both gravity and the depth to groundwater indicate changes in the amount of water stored in an aquifer. For depth-to-groundwater changes, determining the amount of storage change depends on the aquifer-storage coefficient, which is often poorly known and must be estimated based on assumptions about the aquifer. In confined aquifers (those between two impermeable layers), the storage coefficient may be very small, causing large depth-togroundwater changes even if storage change is small. Whereas depth-to-groundwater measurements indirectly indicate aquiferstorage change, gravity change is a direct measurement of the change in total water stored in an aquifer. In most cases, the measured gravity change, in units of acceleration (for example, $\mathrm{m} / \mathrm{s}^{2}$ ), can be converted directly to a change in the thickness of free-standing water, regardless of the depth to groundwater or the aquiferstorage coefficient.

Groundwater levels are measured at a single point, which may or may not be representative of the aquifer. In contrast, the region of sensitivity of a gravity measurement is well defined by Newton's Law and encompasses a large volume of the subsurface. A practical guideline is that sensitivity extends to a radius equal to about 10 times the depth to groundwater.

\section{What Are the Hydrologic Applications?}

Gravity-change data are useful for estimating aquifer-storage change, for estimating recharge in groundwater systems, and for estimating the aquiferstorage coefficient (Pool, 2008).

Aquifer-storage change can be estimated both qualitatively and quantitatively. For example, the gravitychange map on page 2 shows that storage changes are different to the east and west of the groundwater-recharge

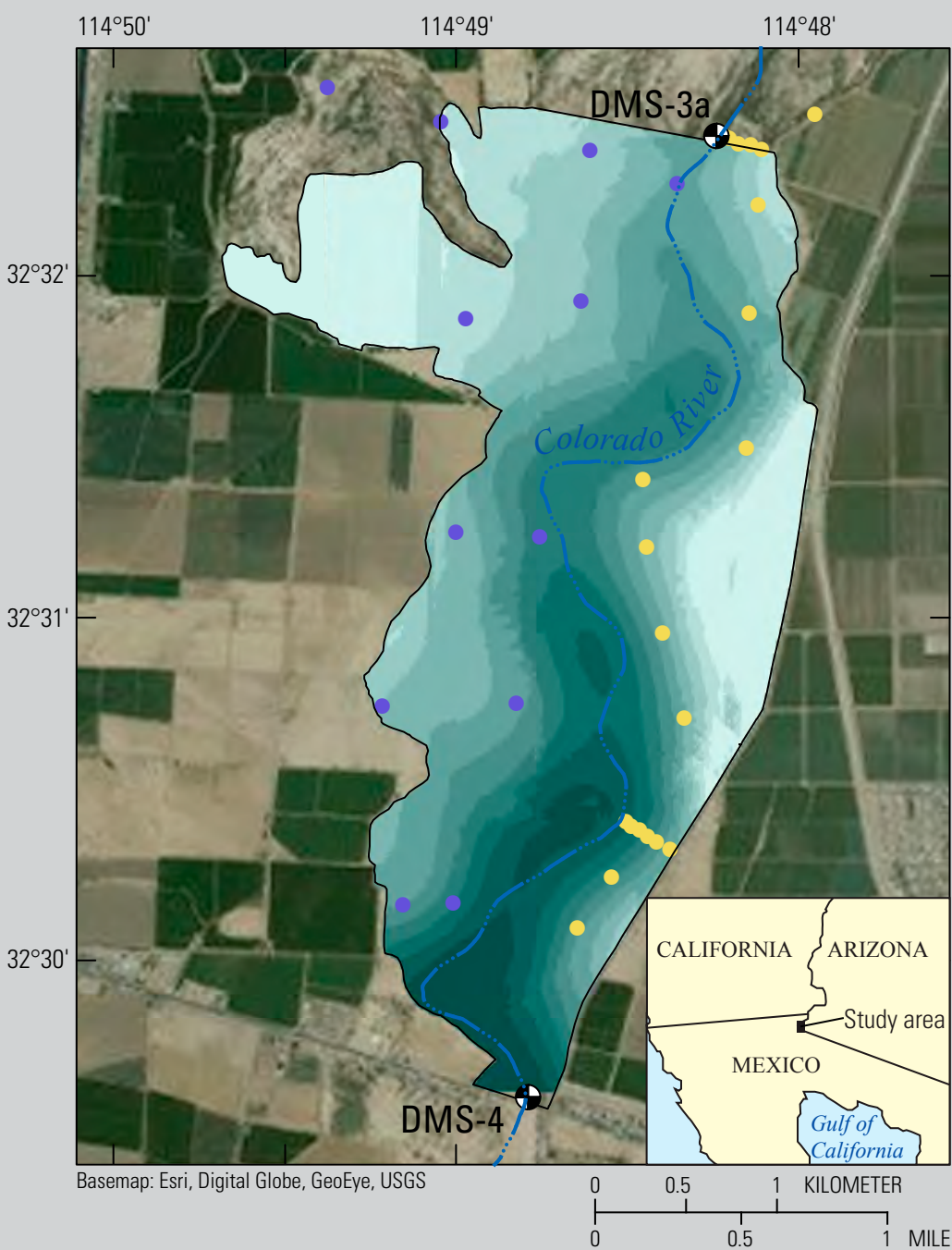

EXPLANATION

Gravity station

- Monitoring well

\section{- Discharge measurement station}

\section{Riparian area boundary}

\section{Storage change, March 20-April 21, 2014,} in meters of water

\begin{tabular}{|llllllllll|l|l|}
0 & 0.25 & 0.5 & 0.75 & 1 & 1.25 & 1.5 & 1.75 & 2 & 2.25 & 2.5 \\
\hline & & & & & & & & & & & \\
\hline
\end{tabular}

This map, overlaid on a satellite image, shows aquifer-storage change beneath the riparian area along the Colorado River near San Luis, Arizona, during the first month of a 2014 experimental "pulse flow" that released about 102 million cubic meters $(82,700$ acre-feet) of water from Morelos Dam on the U.S.-Mexico border into the Colorado River Delta. Gravity-change data were used directly and to determine specific yield to convert measured depth-to-groundwater change to storage change (that is, to convert change in hydraulic head to a thickness of free-standing water). The gravity-derived increase in aquifer storage, $8.4 \times 10^{6}$ cubic meters, agreed well with the decrease in streamflow measured between the two discharge measurement stations shown on the map. (Modified from Kennedy and others, 2016b.) 
facility. This qualitative interpretation is possible because the gravity measurement's region of sensitivity is well known and unaffected by subsurface properties. With other geophysical methods, such as those that depend on the electromagnetic or seismic properties of the Earth, the region of sensitivity changes based on the properties of the subsurface. Quantitative measurements of aquifer-storage change are possible by converting gravity change to an equivalent thickness of water (see map on page 3).

Recharge in groundwater systems is often unknown and must be estimated as a residual component of the groundwater budget after accounting for other inflows and outflows in a system. However, with enough gravity measurements to enable interpolation, recharge can be estimated directly from changes in gravity (Pool and Anderson, 2008).

The aquifer-storage coefficient (specific yield in an unconfined aquifer) is the relation between change in the volume of water per unit area (storage, expressed in units of length) and depth-togroundwater change. It is nearly equivalent to porosity in an unconfined aquifer. Because storage change can be estimated from gravity data, the storage coefficient can be estimated if gravity and depthto-groundwater data are collected at the same location (see graph below).

The unique relation between aquifer-storage change and gravity change (regardless of depth to groundwater or storage coefficient) and the well-known, unchanging region of measurement sensitivity make gravity methods a powerful tool for hydrogeologic investigations. From a practical standpoint, gravity measurements are completely noninvasive and have none of the permitting requirements or potential for contamination that exist when drilling groundwater wells.

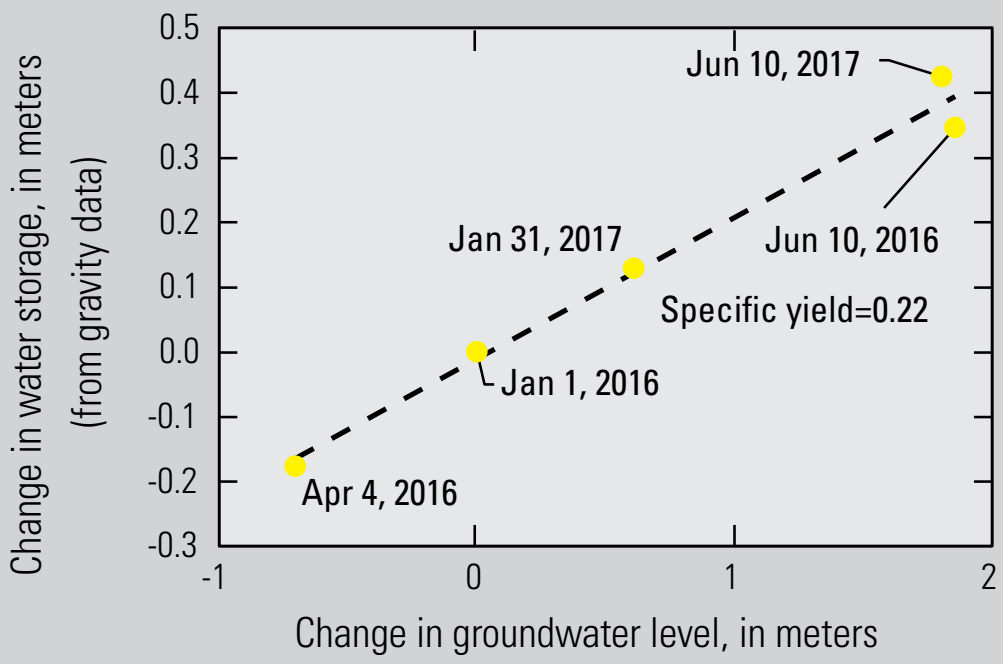

As this graph shows, gravity data can be used to calculate specific yield in an unconfined aquifer. The specific yield is the slope of a best-fit line relating the change in storage (volume of water per unit area) as estimated by the change in gravity to the change in groundwater level (U.S. Geological Survey data from Mesilla Valley, New Mexico).

\section{References Cited}

Kennedy, J.R., Ferré, T.P.A., and Creutzfeldt, B., 2016a, Timelapse gravity data for monitoring and modeling artificial recharge through a thick unsaturated zone: Water Resources Research, v. 52, p. 7244-7261, https://doi. org/10.1002/2016WR018770.

Kennedy, J.R., Rodríguez-Burgueño, J.E., and Ramírez-Hernández, J., 2016b, Groundwater response to the 2014 pulse flow in the Colorado River Delta: Ecological Engineering, v. 106, p. 715-724, https://doi.org/10.1016/j. ecoleng.2016.10.072.
Pool, D.R., 2008, The utility of gravity and water-level monitoring at alluvial aquifer wells in southern Arizona: Geophysics, v. 73, no. 6 , p. WA49-WA59, https://doi. org/10.1190/1.2980395.

Pool, D.R., and Anderson, M., 2008, Ground-water storage change and land subsidence in Tucson Basin and Avra Valley, southeastern Arizona, 19982002: U.S. Geological Survey Scientific Investigations Report 2007-5275, 34 p., https://pubs.usgs.gov/sir/2007/5275/.

\section{Jeffrey R. Kennedy}

Edited by James W. Hendley II Layout by Cory D. Hurd
For more information contact: azgravity@usgs.gov

or

USGS Arizona Water Science Center Directorat dc_az@usgs.gov

https://www.usgs.gov/centers/az-water https://answers.usgs.gov/

1-888-ASK-USGS (1-888-275-8747)

More information on the USGS Southwest Gravity Program (including a complete bibliography) is also available at:

https://go.usa.gov/xqBnQ 